\title{
Miocardite Aguda Secundaria a Feocromocitoma
}

\author{
Lucélia Cunha Magalhães, Eduardo S. Darze,Antônio Ximenes, Oto Santana, \\ Jorge Bastos, Armênio Guimarães \\ Salvador, BA
}

Cardite aguda como manifestação primária de feocromocitoma é uma apresentação rara, com poucos relatos na literatura ${ }^{1}$. Muitos vezes o diagnóstico só é firmado na anatomia patológica e, freqüentemente, confundido com infarto agudo do miocárdio, ou cardite viral. Relatamos um caso de mulher de 40 anos portadora de feocromocitoma, com hipertensão prévia do tipo leve e lábil e que desenvolveu, subitamente, débito cardíaco baixo com arritmias graves e potencialmente letais, cujo acompanhamento permitiu a suspeita e a investigação da condição subjacente. Teve recuperação completa sem seqüelas e sem a realização de exames invasivos, permanecendo a mesma condição de hipertensa da situação anterior.

Feocromocitoma é um tumor funcionante, composto de células cromoafins, que produzem catecolaminas, sendo que a grande maioria delas (85\%) encontra-se na medula da suprarenal. 0 restante ocorre no sistema paragangliônico, que se estende da pelves até a cabeça. O feocromocitoma pode ter origem familiar, em associação com neoplasias endócrinas múltiplas. É uma condição que produz um largo espectro de manifestações clínicas e bioquímicas, a maioria relacionada ao excesso de catecolaminas circulantes de modo paroxístico. Embora a hipertensão seja uma apresentação cardinal, existem relatos da ausência de hipertensão². A grande maioria dos pacientes (75\%) apresenta a tríade súbita clássica, caracterizada, por cefaléia, palpitações e hipertensão grave. A condição é ameaçadora de vida pelas complicações cardiovasculares, principalmente o acidente vascular cerebral do tipo hemorrágico, as arritmias e o comprometimento hemodinãmico do coração. Cardite aguda, como manifestação primária, não é comum e foi inicialmente descrita por Mc-Guinley e cols. em $1987^{3}$ como miocardite norepinefrínica e, posteriormente, por Sardesai e cols., em 1990 como cardiomiopatia induzida por catecolaminas ${ }^{4}$.

\section{Relato do caso}

Mulher branca de 40 anos, comerciaria, solteira, natural e residente em Salvador.

Em março de 2003, foi à consulta com história de palpitações e leves tremores, ambos esporádicos desde outubro do ano anterior,

Endereço para Correspondência: Lucelia Cunha Magalhães - Serviço de Cardiologia Preventiva - Centrocor - Rua Agnelo de Brito, 102 - SI. 101 Federação Salvador, BA - CEP 40210-245

e-mail: luceliamagalhaes@terra.com.br

Recebido para Publicação em: 23/04/2004

Aceito em: 27/04/2004 referindo o período como bastante estressante, às custas do seu novo trabalho. Um mês antes, houve piora dessas queixas, associada à perda do emprego e encerramento de um relacionamento de muitos anos. Referia atividade física moderada e regular, sem queixas. Tinha há 5 anos o diagnóstico de hipertensão leve e lábil, evidenciada por cefaléia occipital durante atividade física, com uso regular desde então de atenolol de $25 \mathrm{mg}$ e hidroclorotiazida de 12,5mg/dia, com excelente controle. Nessa oportunidade foi diagnosticada uma retificação da valva mitral, com escape pelo ecocardiograma. Nunca apresentou nos acompanhamentos bianuais lesão de órgãos alvo. Tabagista desde 1999. Tinha uma importante história familiar de hipertensão, incluindo pais, e, em ambos, com intensa reação de alarme em consultórios médicos. Ao exame físico pulso radial (PR) de $64 \mathrm{bpm}$, regular cheio e pressão arterial de 154/88mmHg média de duas verificações. Mapa, Holter e prova de esforço normais, uma glicemia de $128 \mathrm{mg} / \mathrm{dl}$ e no sumário de urina, 5 piócitos por campo. Estava em uso de tenoretic $25 \mathrm{mg} / \mathrm{manhã} \mathrm{tendo} \mathrm{sido} \mathrm{acrescentado,} \mathrm{atenol}$ $25 \mathrm{mg}$ à noite. Houve melhora com o aumento do atenolol porém 1 mês após a primeira consulta, e de após encerrar atividade física habitual, apresentou intenso mal estar, com taquicardia, sudorese, palidez e dor epigástrica seguidas de lipotímia, tendo sido encaminhada a uma unidade de emergência. Passou a apresentar dor abdominal alta em faixa, náuseas e vômitos freqüentes. Apresentava PR $=92 \mathrm{bpm}$ débil e PA=156/75mmHg. Realizou uma ultra-sonografia do abdômen total, dois eletrocardiogramas, dosagens de amilase, enzimas cardíacas, hepáticas e musculares normais, com um leucograma de 28.000, com ausência de eosinófilos. Foi transferida para um hospital geral e no fim do dia apresentou troponina de $9 \mathrm{ncg} / \mathrm{dl}$ e depois de 10, manteve leucograma elevado com o mesmo padrão. Passou a apresentar leve hipotensão, realizando mais dois eletrocardiograma normais e o ecocardiograma revelou câmaras de dimensões normais, com acinesia de todos os segmentos miocárdicos, à exceção dos segmentos apicais, que se encontravam hipercinéticos, disfunção sistólica importante e hipertensão pulmonar moderada. Teve a suspeita de cardiopatia aguda, provavelmente, de origem viral, tendo iniciado o tratamento para a disfunção ventricular, com resposta excelente (captopril $25 \mathrm{mg}$, BID e furosemida 40mg/dia) e tendo sido solicitado uma cintilografia miocárdica com o gálio-67 para confirmar miocardite viral.

Desapareceram as queixas e o quadro hemodinâmico tornouse estável. No $3^{\circ}$ dia de internamento desenvolveu arritmias, tipo fibrilação atrial, taquicardia atrial paroxística e períodos de taquicardia ventricular bidirecional (fig. 1) Nessa oportunidade já havia ocorrido normalização total da função ventricular, pela clínica, corroborado, pelo ecocardiograma, bem como, normalização do 
leucograma e da troponina. A cintilografia pelo teste do gálio (fig. 2) evidenciou miocardite aguda em atividade e dois dias após, a sorologia para vírus revelou títulos elevados para Coxsackie $B$, frações 2 e 5 tipo IgG. Dias depois, apesar do tratamento antiarrítmico, antihipertensivo e o uso de altas doses de ansiolítico, fez crise aguda de tremores, com palidez e hiperfonese intensa das bulhas, exacerbação do sopro sistólico em ponta com sensação de morte eminente, intensa agitação motora e logo após, períodos de taquicardia ventricular sustentada com $P A=260 / 110 \mathrm{mmHg}$ e $\mathrm{PR}=48 \mathrm{bpm}$ filiforme. Solicitadas imediatamente dosagens séricas de adrenalina, noradrenalina e metanefrinas urinárias de $24 \mathrm{~h}$. Com a introdução de mexitil 900mg associado a 600mg de miodarona houve estabilização do ritmo. Seis dias após, com os resultados apresentados de leve aumento de catecolaminas e seus metabólicos, (adrenalina=21ng, normal de 0-16, noradrenalina $=90$, normal de 11-86ng) foi solicitado tomografia computadorizada do abdômen, investigando a cadeia simpática e as suprarenais. A tomografia computadorizada mostrou tumor da suprarenal à direita sugestivo de feocromocitoma. Após bloqueio alfa adrenérgico com prazozim foi realizada adrenalectomia com sucesso (fig. 3 e 4). No momento encontra-se assintomática, voltou à sua condição de hipertensa leve e lábil, com uso de ramipril $5 \mathrm{mg}$ e hidroclorotiazida $12,5 \mathrm{mg}$ ao dia.

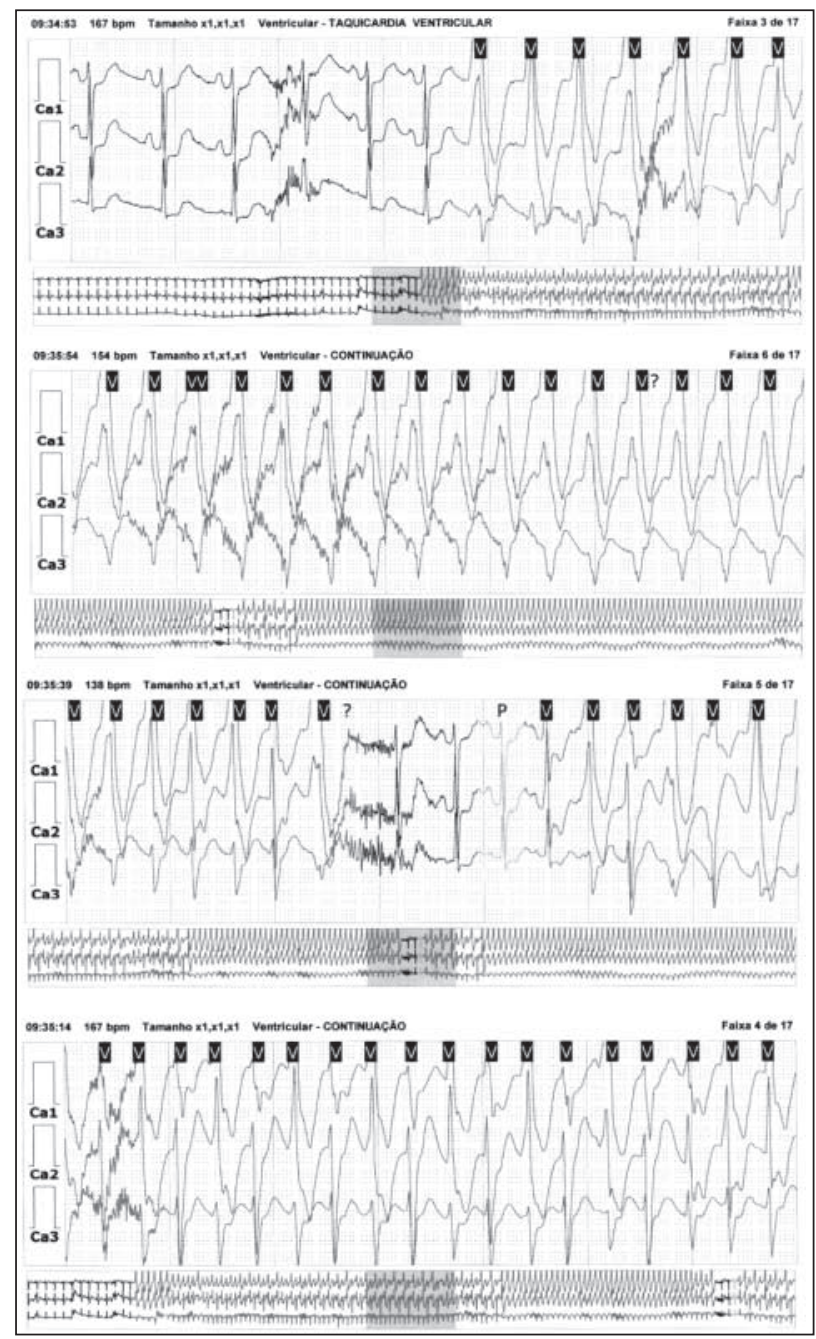

Fig. 1 - Taquicardia ventricular paraxística com até 118 batimentos e FC de 167 bpm, monomórficas e com aspecto bidirecional (15/05/2003, 9h 34').

\section{Discussão}

Não existem dados sobre a prevalência de manifestação primária de cardite aguda noradrenérgica pelo feocromocitoma, porém se sabe que ocorre em menos de $5 \%$ da apresentação de feocromocitoma ${ }^{5,6}$. Neste caso, alguns aspectos chamam à atenção: A ausência de cefaléia, tida como o mais comum sintoma de feocromocitoma. Em hipertensa prévia, a inexistência de crises hipertensivas graves e resistente à terapia. A forma de manifestação

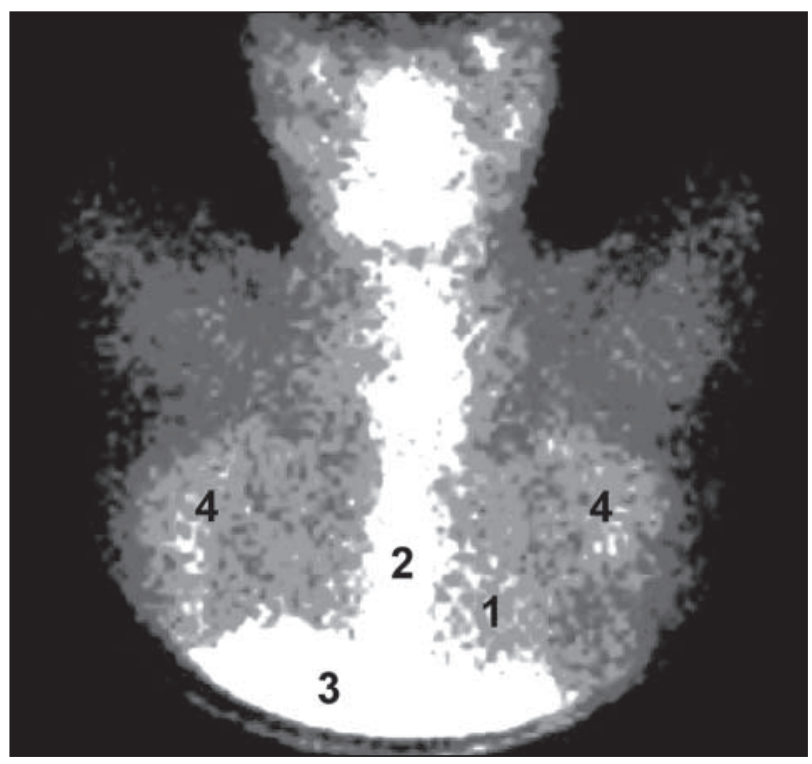

Fig. 2 - Imagens cintilográficas do tórax 72h após administração venosa - Alta probabilidade de miocardite em atividade. Legenda da cintilografia com Gálio-67: 1 - coração; 2 - esterno; 3 - fígado; 4 - mamas.

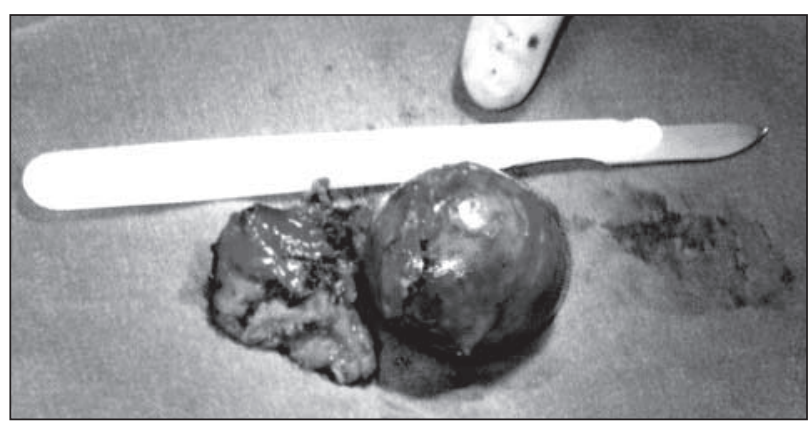

Fig. 3 - Peça anatômica do tumor (Feocromocitoma) acoplada a suprarena direita, retirada dia 23 de maio de 2003.

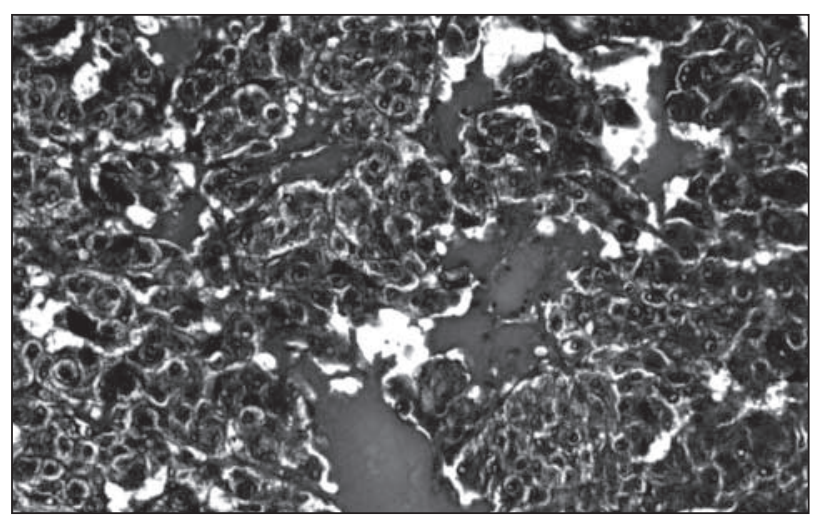

Fig. 4 - Corte de microscopia óptica, mostrando feocromócitos típicos em padrão trabecular, intercalados com vasos sangüíneos congestos e hemorragia coloração por hematoxilina-eosina e aumento 200x. 
inicial com dor abdominal em faixa, sudorese, hipotensão e vômitos nos levou a investigar pancreatite ou úlcera gástrica complicada. Após algumas horas, o quadro se concentrou na área cardíaca, com troponina bastante elevada, desconforto retroesternal associado ao abdominal e sinais de baixo débito cardíaco. 0 eletrocardiograma e os aspectos epidemiológicos cardiovasculares levaramnos a privilegiar o ecocardiograma ao invés do estudo hemodinâmico, que, na ocasião, levantávamos a possibilidade de cardite, uma vez que na presença de coronarite e pancardite, o contraste utilizado no estudo hemodinâmico poderia comprometer ainda mais agudamente a função do ventrículo esquerdo. Surpreendeunos a arritmia diversificada, grave e resistente à terapia, na ausência de disfunção de ventrículo esquerdo, e, especialmente, a ocorrência de cardite viral em adultos, que não é uma manifestação usual. A cadência temporal, apresentada no $15^{\circ}$ dia de internamento, pela $1^{\text {a }}$ vez vivenciada pelo médico assistente em todo o seu ciclo, nos fez pensar em algo que, agudamente, circulava e produzia esses achados, passando ser um quadro clássico de descarga adrenérgica aguda e disfuncional. A cadência temporal era: mal estar indescritível, tremor involuntário, taquicardia sinusal com pulso filiforme, hiperfonese de bulhas, aumento importante de sopro sistólico (de protomeso grau II a holosistólico, grau IV) com ictus valvular, porem muito impulsivo e que, somente após 4min da manifestação, aparecem as arritmias; primeiro, como extra-sístoles ventriculares isoladas, depois aos pares e logo, em seguida taquicardia ventricular sustentada bidirecional com baixo débito.

A cintilografia pelo galio-67, sugerindo miocardite aguda em atividade, foi interessante, pois este achado só tinha sido classicamente descrito, nas miocardites agudas na infância prioritariamente do tipo viral e ausência de descrição em caso de feocromocitoma, na literatura consultada.

Os títulos elevados de IgG para Coxsackie B frações 2 e 5 ficaram de difícil interpretação, ou um achado associado sem relação causal com a miocardite ou a situação de exaustão do sistema imune pelos hormônios do estresse teriam levado à ocorrência da miocardite viral aguda.

\section{Referências}

1. Baratella MC, Menti L, Angelini A, et al. An unsual case of myocarditis. Intern Cardiol. 1998;65:305-10.

2. Williams DT, Dann S, Wheeler MH. Phaeochromocytoma-views on current management EJSO. 2003;29:483-90

3. Imperato-Mcginley J, Gautier T, Ehlers K. Reversibility of catecholamines-induced dilated cardiomypathy in a child with phaeochromocytoma. N Engl Med. 1987;316:793-7.
4. Sardesai SH, Mourant AJ, Sivathandon Y, et al. Phaeochromocytoma and catecholamines-induced cardiomypathy presenting as heart failure Br Heart J. 1990; 63:234-7.

5. Ganguly PK, Beanish RE, Dhalla NS. Catecholamine cardiotoxicity in phaeochromocytoma. Am Heart J. 1989;117:1399-400.

6. Salathe M, Weiss P, Ritz R. Rapid reversal of heart failure in a patient with phaeochromocytoma and catecholamines-induced cardiomypathy who was treated with captopril.Br Heart J. 1992; 68:527-8. 